
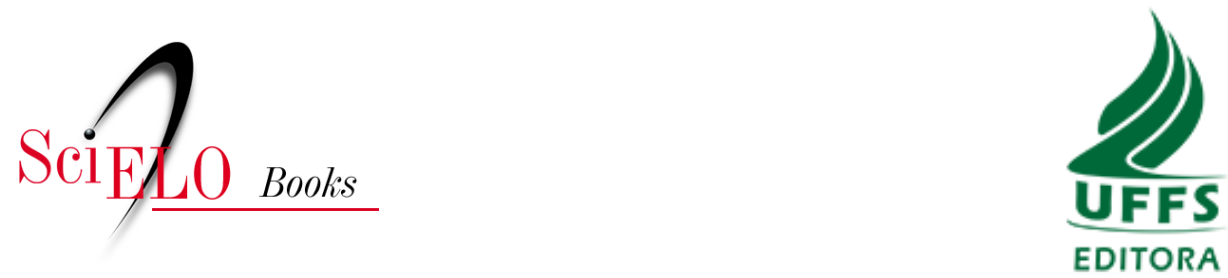

\title{
Políticas de acesso e ações afirmativas na universidade federal da fronteira sul
}

\author{
Rosileia Lucia Nierotka \\ Joviles Vitório Trevisol
}

\section{SciELO Books / SciELO Livros / SciELO Libros}

NIEROTKA, R.L., and TREVISOL, J.V. Políticas de acesso e ações afirmativas na universidade federal da fronteira sul. In: Ações afirmativas na educação superior: a experiência da Universidade Federal da Fronteira Sul [online]. Chapecó: Editora UFFS, 2019, pp. 6594. ISBN: 978-65-5019-009-5. https://doi.org/10.7476/9786550190071.0004.

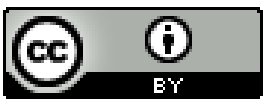

All the contents of this work, except where otherwise noted, is licensed under a Creative Commons Attribution 4.0 International license.

Todo o conteúdo deste trabalho, exceto quando houver ressalva, é publicado sob a licença Creative Commons Atribição 4.0. 


\section{POLÍTICAS DE ACESSO E AÇÕES AFIRMATIVAS NA UNIVERSIDADE FEDERAL DA FRONTEIRA SUL}

As tarefas da democratização do acesso são, assim, particularmente exigentes porque questionam a universidade no seu todo, não só quem

a frequenta, como os conhecimentos que são transmitidos a quem a frequenta. Boaventura de Sousa Santos

A intenção neste capítulo é apresentar, primeiramente, uma contextualização sobre o processo de criação da UFFS, como um projeto de uma política pública de educação superior. Será enfatizada a luta histórica dos movimentos sociais pelo acesso à educação superior pública para uma região que ficou à margem desse acesso por muitos anos, a Mesorregião Grande Fronteira do Mercosul. Num segundo momento, o propósito é apresentar uma trajetória com as características das políticas de acesso adotadas pela UFFS nos primeiros anos de sua existência.

\section{CRIAÇÃO DA UFFS: ALGUMAS CONSIDERAÇÕES}

O processo de criação da Universidade Federal da Fronteira Sul diferencia-se das demais instituições de educação superior brasileiras, especialmente devido ao fato de que sua criação foi decorrente da forte participação da sociedade civil organizada, em particular os movimentos 
sociais. Trata-se, portanto, de um projeto de universidade pública, com um cunho público e "popular" desde suas origens, destinada ao atendimento das camadas populares de uma região que historicamente não teve acesso à educação superior pública: a Mesorregião Grande Fronteira do Mercosul. De acordo com Trevisol, Cordeiro e Hass (2011, p. 31), a origem da UFFS se deu "[...] no âmago da sociedade civil organizada. Ela nasce de 'fora para dentro'; surge dos movimentos sociais e, na sequência, legitima-se como instituição pública estatal por meio da Lei Federal n 12.029/2009”.

As características que marcam a origem da UFFS influenciaram marcadamente o seu projeto político institucional, conforme sinalizam Trevisol e Ló (2013, p. 7):

[...] o lugar (geográfico, político e social) de nascimento da UFFS está longe de ser algo irrelevante. Além de inseri-la na história do Ensino Superior brasileiro como a primeira universidade pública federal nascida dos movimentos sociais, tal fator atua decisivamente sobre a construção de sua identidade.

A Mesorregião Grande Fronteira do Mercosul e o seu entorno, espaço em que a Universidade está inserida, está localizada na fronteira com a Argentina, contemplando 396 municípios e abrangendo as regiões do sudoeste do Paraná, o oeste de Santa Catarina e o noroeste do Rio Grande do Sul, com uma população de cerca de quatro milhões de habitantes, conforme dados obtidos no site do Fórum Mesorregião Grande Fronteira do Mercosul $^{1}$. Trata-se de uma região que ainda concentra significativa parte de sua população na zona rural. Em linhas gerais a mesorregião se caracteriza pelo:

[...] empobrecimento relativo, pressão dos sistemas produtivos sobre os recursos naturais; crescente perda de dinamismo da economia regional ante o contexto de globalização e empobrecimento social, decorrente da dificuldade de inserção das pequenas propriedades rurais no mercado e das precárias condições de moradia de parcela

1 Disponível em: <http://mesomercosul.org.br/mesoregiao.asp>. Acesso em: 09 out. 2014. 
significativa da população, caracterizadas pelas deficiências de saneamento básico e falta de acesso à saúde e à educação. Como consequência dos fatores elencados, advém a baixa capacidade de absorção de mão-de-obra e retenção da população, que leva ao êxodo rural e à emigração regional (FÓRUM MESORREGIÃO GRANDE FRONTEIRA DO MERCOSUL, 2014, p. 1).

No que se refere à educação, conforme análise de Trevisol, Cordeiro e Hass (2011, p. 42), "trata-se de uma região historicamente desassistida pelo poder público, especialmente no que diz respeito ao acesso à Educação Superior, considerada pelo Ministério da Integração Regional como uma área em depressão econômica”.

Ao retratar o processo de implementação e criação da UFFS, é necessário traçar um resgate histórico de algumas mobilizações, iniciativas e ações desenvolvidas por um conjunto de pessoas, principalmente pelos movimentos sociais e demais lideranças políticas e comunitárias em prol do acesso à educação superior pública para a região.

O contexto em que esse processo se insere não é tão recente, pois a luta pela causa da educação superior pública para a região remonta ao final da década de 70. Conforme Trevisol (2014), a partir do final dos anos de 1960 foram criadas as primeiras faculdades na região, constituindo-se como fundações públicas de direito privado. Mais tarde foram surgindo IES públicas (federais e estaduais), porém situadas em cidades mais populosas da região. Dessa forma, a educação superior pública era destinada majoritariamente aos estudantes oriundos das classes médias e das escolas privadas. E o ensino privado, destinado àqueles que possuíam condições de subsidiar o pagamento das mensalidades.

As mobilizações e iniciativas pela interiorização e expansão da educação superior pública foram ocorrendo em várias regiões dos estados do Sul do país, e essa demanda foi sendo respondida pela criação de IES de direito privado, mas especificamente as comunitárias, implementadas pelos poderes públicos municipais (TREVISOL, 2014). 
A década de 80 é marcada pela crise da economia agrícola familiar e foi se acentuando o processo de êxodo rural, em que muitos jovens saíram do campo em direção às grandes cidades em busca de trabalho assalariado (TREVISOL, 2014).

O caráter elitista e privatizado da educação superior pública, que excluía milhares de jovens da obtenção de um diploma universitário, foi ainda reforçado, a partir da década de 90 , com as políticas neoliberais e com a flexibilização da legislação educacional, que permitiu o estímulo ao crescimento das IES privadas. Assim, por décadas, as pressões populares mantiveram-se, e, por vezes, com suas expectativas abortadas de ter uma universidade pública na região da Messorregião Grande Fronteira do Mercosul (TREVISOL, 2014).

Com a tomada de posse do Presidente Lula, em 2003, iniciaram-se muitas mudanças nas políticas educacionais destinadas à educação superior, a partir do compromisso assumido nas propostas desse governo para a democratização, expansão e interiorização da educação superior pública brasileira. Além disso, o Plano Nacional de Educação (2001-2010) também apontava como uma de suas metas a necessidade de ampliação das matrículas de educação superior aos jovens de 18 a 24 anos no setor público (TREVISOL, 2014).

Aliada à convicção de que a região carecia de educação superior pública, uma das motivações para a luta por uma universidade pública na região foi a vinda do Presidente da República à cidade de Chapecó, para abertura da Exposição-Feira Agropecuária, Industrial e Comercial de Chapecó (EFAPI), em 2003. Nesse ato, o presidente Lula manifestou publicamente que haveria uma universidade federal no Oeste catarinense. Conforme Trevisol (2014, p. 10) "o aceno de Lula passou a ser uma vitória para as lideranças e organizações que vinham, há décadas, construindo o convencimento público sobre a importância de uma IES pública para a região. A pauta antiga e restrita passou a ser contemporânea, pública e estatal”. 
A partir do compromisso sinalizado pelo Presidente da República, as mobilizações em torno da possibilidade de haver uma universidade na região foram se intensificando, e, em 2005, foi criado o Movimento Pró-Universidade Federal (MPUF), integrando lideranças dos três estados do Sul, pois a orientação do Ministro de Educação foi a unificação desses movimentos em torno de uma única proposta de universidade para a região. $\mathrm{O}$ movimento foi coordenado pela Federação dos Trabalhadores na Agricultura Familiar da Região Sul (FETRAF-SUL) e pelo Movimento Sem Terra (MST). Além destas organizações, juntava-se também ao movimento o Fórum da Mesorregião, igrejas, universidades, sindicatos, vereadores, deputados, senadores, associações e movimento estudantil (TREVISOL, 2014).

Ainda em 2005, foi apresentado à Câmara dos Deputados, pela autoria do Deputado Federal Cláudio Vignatti, o projeto de Lei no $6.037 / 2005$, tendo como proposição a criação da Universidade para a Mesorregião Grande Fronteira do Mercosul. A proposta foi articulada e discutida conjuntamente com as lideranças regionais que concluíram que "este projeto causaria grande desenvolvimento econômico, social, cultural, científico e tecnológico, além de proporcionar investimentos públicos expressivos no único território de escala mesorregional na macrorregião sul ainda não contemplado com IES públicas" (TREVISOL; LÓ, 2013, p. 28).

Em maio de 2006, o então reitor da UFSC emitiu a Portaria no 356/ GR/2006 constituindo um Grupo de Trabalho que ficou com a responsabilidade de elaborar um projeto técnico para a construção da futura Universidade, tendo como data-limite dia 31 de dezembro daquele mesmo ano, sendo em seguida prorrogado até 31 de agosto de 2007. Em junho de 2006, o Presidente Lula, em nova visita à cidade de Chapecó, momento em que participou do II Encontro Nacional da Habitação da Agricultura Familiar, manifestou-se de forma positiva quanto à criação da universidade (TREVISOL, 2014).

Ainda, em junho do ano de 2006, conforme Benincá (2011), o Ministro Haddad aprovou a ideia da criação de uma universidade federal 
para a Mesorregião Grande Fronteira do Mercosul, porém, em 2007, voltou atrás, propondo a criação de um Instituto Federal. O movimento não aceitou essa proposta, por entender que era necessária uma universidade para atender a demanda regional de educação superior. Para aquele momento ficou acertada a criação de uma Comissão para a elaboração de um projeto de criação da Universidade, que fora instituída oficialmente por meio de uma Portaria do MEC, n 948, em 26 de novembro de 2007, com um prazo de três meses para a conclusão dos trabalhos. Essa Comissão foi composta por 11 integrantes do Movimento Pró-universidade, além de técnicos do MEC e de representantes da Universidade Federal de Santa Maria (UFSM) e da Universidade Federal de Santa Catarina (UFSC).

Após um período de diálogo e negociações com o MEC, em julho de 2008, o Projeto de Lei de Criação da UFFS foi assinado pelo Presidente Lula e encaminhado ao Congresso Nacional. E, no ano de 2009, foi empossada pelo Ministro de Educação a Comissão de Implantação da UFFS, tendo como presidente dessa comissão o professor Dilvo Ristoff, da Universidade Federal de Santa Catarina (BENINCÁ, 2011).

No histórico institucional da UFFS, o que também é mencionado nos projetos pedagógicos dos $\operatorname{cursos}^{2}$, consta:

Os anos de 2008 e 2009 foram marcados por intensa mobilização do Movimento Pró-Universidade no sentido de estabelecer o perfil da Universidade a ser criada, a localização de seus campi e a proposta dos primeiros cursos a serem implantados; pelo acompanhamento, no âmbito do governo federal, dos trâmites finais da elaboração do projeto a ser submetido ao Congresso Nacional; pela negociação política a fim de garantir a aprovação do projeto da Universidade na Câmara dos Deputados e no Senado Federal.

2 Decisão n. 2/2014 - CONSUNI/CGRAD - Autoriza a alteração do texto do Histórico Institucional da UFFS constante dos projetos pedagógicos dos cursos de graduação. Disponível em: <http://www.uffs.edu.br/images/SECOC/ Deciso_02-2014_-_Autoriza_a_alterao_do_Histrico_Institucional_nos_PPCs.pdf >. Acesso em: 3 out. 2014. 
Em 15 de setembro de 2009, por meio da Lei no 12.029/2009, o então Presidente da República Luis Inácio Lula da Silva cria a UFFS. A Universidade Federal de Santa Catarina foi designada como IES tutora da UFFS, sendo o professor Dilvo Ristoff nomeado como o primeiro reitor pro tempore da UFFS ${ }^{3}$. A Universidade já nasceu multicampi, com sua sede na cidade de Chapecó, e com os demais campi situados nas cidades de Laranjeiras do Sul, Realeza, Cerro Largo e Erechim (BRASIL, 2009).

Ainda naquele mesmo ano foram realizados os primeiros concursos públicos para prover os cargos de docentes e de técnicos administrativos, assim como também teve início o primeiro processo seletivo para estudantes, haja vista a decisão de iniciar as aulas em março de 2010.

Em 24 de novembro de 2009, o reitor da UFFS publicou a Portaria no 044/UFFS/2009, que aprovou a criação de 42 cursos para a UFFS, distribuídos nos seus cinco campi (UFFS, 2009a). E, no dia seguinte, foi lançado o primeiro edital de seleção dos futuros estudantes da UFFS (Edital $\left.n^{\circ} 003 / U F F S / 2009\right)$, para o primeiro semestre de 2010.

A UFFS, desde o seu projeto de criação, primou pelo seu caráter popular e inclusivo, assumindo compromissos com o atendimento das camadas populares e o desenvolvimento regional. Importante salientar que um dos aspectos fundamentais para a estruturação e definição de um projeto institucional na UFFS foi a participação social. Os diversos setores envolvidos com o processo de criação da Universidade foram articulando suas contribuições em torno de uma proposta que foi sendo definida e reconhecida como de uma "universidade popular". Essa expressão foi estruturando um conjunto de expectativas, princípios e diretrizes da Universidade (TREVISOL, 2015).

Os princípios norteadores do Projeto Político Institucional (PPI) da UFFS $^{4}$ expressam a sua origem, o seu contexto e quais são as suas finalidades. Na sua íntegra os princípios norteadores do PPI da UFFS são os seguintes:

\footnotetext{
3 Permaneceu no cargo até fevereiro de 2011, sendo em seguida substituído pelo Prof. Jaime Giolo.
}

4 Disponível em: <http://antiga.uffs.edu.br/wp/?page_id=83>. Acesso em: 02 out. 2014. 
1 Respeito à identidade universitária da UFFS, o que a caracteriza como espaço privilegiado para o desenvolvimento concomitante do ensino, da pesquisa e da extensão;

2 Integração orgânica das atividades de ensino, pesquisa e extensão desde a origem da instituição;

3 Atendimento às diretrizes da Política Nacional de Formação de Professores do Ministério da Educação, estabelecidas pelo Decreto $\mathrm{n}^{\circ}$. 6.755, de 29 de janeiro de 2009, cujo principal objetivo é coordenar os esforços de todos os entes federados no sentido de assegurar a formação de docentes para a educação básica em número suficiente e com qualidade adequada;

4 Universidade de qualidade comprometida com a formação de cidadãos conscientes e comprometidos com o desenvolvimento sustentável e solidário da Região Sul do País;

5 Universidade democrática, autônoma, que respeite a pluralidade de pensamento e a diversidade cultural, com a garantia de espaços de participação dos diferentes sujeitos sociais;

6 Universidade que estabeleça dispositivos de combate às desigualdades sociais e regionais, incluindo condições de acesso e permanência no ensino superior, especialmente da população mais excluída do campo e da cidade;

7 Uma universidade que tenha na agricultura familiar um setor estruturador e dinamizador do processo de desenvolvimento;

8 Uma universidade que tenha como premissa a valorização e a superação da matriz produtiva existente;

9 Uma universidade pública e popular;

10 Uma universidade comprometida com o avanço da arte e da ciência e com a melhoria da qualidade de vida para todos (UFFS, 2015d).

O PPI da UFFS expressa o compromisso com a região, no sentido de contribuir para a redução das desigualdades sociais e com a democratização das condições de acesso e da permanência dos estudantes. Para Trevisol, Cordeiro e Hass (2011, p. 32),

[...] trata-se, portanto, de uma Universidade que nasce da sociedade, para ser um bem público a seu serviço. Significa concebê-la e 
realizá-la tendo como ideia-força o princípio da democratização, cuja processualidade precisa se dar a partir de dois movimentos. $\mathrm{O}$ primeiro deles, o da democratização de dentro para fora, exige que a UFFS seja construída a partir de uma relação interativa e solidária (e não unilateral e distante) com a sociedade. [...] O segundo movimento, o da democratização de fora para dentro, implica romper com as formas tradicionais e hegemônicas de conceber a universidade. O mesmo movimento que leva o conhecimento científico para a sociedade deve ser o que traz outras formas de conhecimento para dentro da Universidade.

\section{O caráter popular da UFFS está presente em todo o processo de cria-} ção e expresso nos documentos que lhe deram origem. Em entrevistas sobre a dimensão popular da UFFS, duas lideranças que participaram do processo de criação, assim se referiram:

O popular vem desta visão de que os grandes setores sociais nunca tiveram vez e voz no nosso país então esse popular, é isso mesmo é dar vez e voz a quem nunca teve espaço, a quem não conseguiu chegar a uma universidade, a quem não é filho de classes sociais que tem condições de pagar uma universidade porque hoje nós temos no máximo quinze a vinte por cento da população consegue chegar a uma universidade. Então é isso mesmo então é desde o acesso. ${ }^{5}$

Nós não queremos uma universidade que esteja dissociada da comunidade, que esteja encastelada, que esteja longe da sociedade, que esteja acima da sociedade, uma universidade arrogante, que faz da ciência um lugar de dominação. [...] não queremos uma universidade que fragmenta o conhecimento, e nesta fragmentação, do mundo, ao fragmentar, impede a construção da consciência, que depende do todo; não queremos uma universidade elitizada e corporativista. ${ }^{6}$

Como já foi assinalado, o termo "popular" situa-se no processo de criação da UFFS e seu sentido, longe de estar esgotado, está ainda sendo investigado.

5 Depoimento de uma das lideranças que participou do Movimento Pró-Universidade Federal, em entrevista realizada pelos pesquisadores Joviles Vitório Trevisol e Marcelo Ló, em 2013 (TREVISOL; LÓ, 2013, p. 63; 2015).

6 Depoimento de uma das lideranças que participou do Movimento Pró-Universidade Federal, em entrevista realizada pelos pesquisadores Joviles Vitório Trevisol e Marcelo Ló, em 2013 (TREVISOL; LÓ, 2013, p. 133; 2015). 
Salienta-se que não é o foco principal dessa pesquisa, mas cumpre assinalar algumas reflexões acerca desse tema. Pereira (2014) associa o debate acerca do conceito de "popular" no campo da "Educação Popular" e como uma resposta ao elitismo na universidade brasileira, tendo as classes populares como atores principais nesse processo. Nesse sentido, entende a universidade como um espaço social de resistência dos oprimidos, tendo em vista que ela primordialmente foi um espaço ocupado pelas elites no contexto brasileiro. Conforme o autor, "é possível estabelecermos uma relação potente entre a ideia de universidade popular e a classe trabalhadora, tendo em vista que o popular se constrói em oposição à elite” (PEREIRA, 2014, p. 96).

Para o autor, a experiência da UFFS na condição de universidade popular é algo que precisa ser avaliado com o tempo, pois se trata de uma instituição ainda muito jovem. Contudo, assinala a seguinte reflexão:

[...] a preponderância de estudantes originários da escola pública, de jovens no interior do país, de comunidades camponesas ligadas à agricultura familiar, enfim, de segmentos historicamente excluídos do acesso à universidade, principalmente a pública, além do envolvimento inicial do Movimento Pró-Universidade, podem contribuir para a criação de uma instituição que promoverá avanços na relação entre os saberes populares e acadêmicos (PEREIRA, 2014, p. 100).

Nessa mesma direção de análise, situa-se uma reflexão acerca do termo "popular" desenvolvido por Trevisol e Martins (2015, p. 11). Segundo eles, o termo "popular" denota, entre outros sentidos, o "[...] distanciamento com o elitismo reinante na maioria das instituições de ensino superior no Brasil e no mundo. Ao longo de séculos, as universidades têm sido, com raras exceções, espaços ocupados pelas elites detentoras do capital econômico, social e cultural". Para os autores, a concepção de "popular":

Traz para dentro do projeto uma concepção dialética e não positivista de conhecimento e de educação superior. Partilha do entendimento de que todas as formas de conhecimento, inclusive o saber científico, são construções sociais coletivas, que precisam estar a 
serviço da sociedade. O conhecimento, neste sentido, produz transformação social, emancipação humana e autonomia (TREVISOL; MARTINS, 2015, p. 11).

Esse mesmo sentido é reforçado por Dilvo Ristoff, primeiro reitor pro tempore da UFFS, em fala proferida em 2010: “a UFFS nos coloca diante de uma oportunidade histórica, maravilhosa e ímpar, de ajudar a melhorar a educação dos três estados do Sul e ajudar a região a chegar a um novo patamar de desenvolvimento econômico, social, científico e cultural" (UFFS, 2010a, p. 3).

\section{POLÍTICAS DE ACESSO E AÇÕES AFIRMATIVAS}

A política de acesso foi discutida durante o processo de elaboração do Projeto Político Institucional da UFFS. Tendo em vista os compromissos assumidos com a inclusão social, era fundamental definir uma política que possibilitasse aos filhos dos trabalhadores acessarem a educação superior.

Um dos princípios constantes no primeiro Estatuto da Universidade é a "igualdade de condições para o acesso e permanência na Educação Superior" (UFFS, 2010b, p. 3). Tendo em vista a característica central de se afirmar como uma universidade popular, a UFFS optou desde o início pela utilização do ENEM, como um primeiro passo para o processo seletivo de seus estudantes, em detrimento do tradicional vestibular. Além do ENEM, a Universidade implantou como uma primeira ação afirmativa, a modalidade de bonificação com o critério de escola pública, conhecida como "Fator Escola Pública", que consistiu num acréscimo de $10 \%$ sobre a nota final do ENEM para cada ano de ensino médio estudado em escola pública.

Essa foi uma decisão construída pelos movimentos sociais, que tinham como meta a inclusão social de grupos que ao longo de suas histórias ficaram longe do acesso à educação superior pública. Dilvo Risttof ${ }^{7}$,

7 Foi uma das lideranças que participou do Movimento Pró-Universidade Federal. Concedeu entrevista aos pesquisadores Joviles Vitório Trevisol e Marcelo Ló, em 2013 (TREVISOL; LÓ, 2013; 2015). 
que presidiu a Comissão de Implantação da UFFS, enfatizou que essa escolha decorreu de uma reflexão sobre alguns números que caracterizavam a realidade da educação brasileira, mais especificamente, o percentual de estudantes que cursavam o ensino médio público, sendo $89 \%$. Esse foi um aspecto central para o desenho da política de acesso da UFFS, com a finalidade de beneficiar quem é oriundo da escola pública, buscando romper com o elitismo das universidades federais. Para Risttof, o sentido dessa política de acesso é “a universidade pública a serviço do ensino básico público" (TREVISOL; LÓ, 2013, p. 72).

Essa modalidade de política de acesso ficou conhecida como "cota social”. Nas palavras de Rotta, Victel e Andrioli (2012, p. 61):

O "Fator Escola Pública" se constituiu em uma modalidade de cota social com o objetivo de proteger o estudante em situação de hipossufiência educacional. Parte da ideia de que o Brasil enfrenta hoje uma precariedade da Educação Básica pública, o que coloca os alunos provenientes da mesma em condições desfavoráveis para tentar o acesso ao Ensino Superior público pelos mecanismos convencionais existentes. [...] Dados apontam que $89 \%$ dos alunos do ensino médio estão nas escolas públicas, enquanto nas universidades públicas, federais e estaduais, $76 \%$ das vagas são ocupadas por alunos oriundos de escolas particulares.

A partir dessa consideração, Pereira (2014, p. 156) ainda complementa:

A constatação de que a escola pública sofre com problemas na atualidade não significa que as escolas privadas sejam todas de melhor "qualidade", mas que estas ao operarem na lógica da clientela, vendendo um serviço, desenvolvem preocupações instrumentais com a aprovação de seus alunos em processos seletivos às universidades. Se uma universidade federal apenas criar vagas e realizar processos seletivos, seja por provas próprias ou pelo ENEM, desconsiderando as assimetrias no percurso escolar dos estudantes, poderá estar reproduzindo uma lógica excludente que se esconde atrás da aparente "justa concorrência" de testes iguais para candidatos iguais (com o ensino médio concluído). 
Nessa mesma direção, Romão e Loss (2014) consideram que o processo Seletivo da UFFS, tendo como ponto de partida o ENEM, seguido da bonificação, com base na escola pública, promove uma verdadeira "discriminação positiva”.

A aplicação do "Fator Escola Pública” tem por base a seguinte regra:

I) FatorEP = 1,3 - para o candidato que declarou ter cursado integralmente, com aprovação, todo o ensino médio em escola pública; II) FatorEP = 1,2 - para o candidato que declarou ter cursado, com aprovação, apenas (duas) séries do ensino médio em escola pública; III) FatorEP = 1,1 - para o candidato que declarou ter cursado, com aprovação, apenas (uma) série do ensino médio em escola pública; IV) FatorEP = 1,0 - para os demais candidatos (UFFS, 2009b, p. 4).

Conforme destacam Haas e Linhares (2012, p. 839), a adoção de ações afirmativas, no Brasil, busca, de modo geral, "mitigar a incontestável desigualdade social brasileira, visando a atacar e corrigir distorções que se encontram numa das causas dessa desigualdade - a maneira como nosso sistema educacional está estruturado". Portanto, "a relevância do tema expõe o papel da universidade brasileira e de sua responsabilidade diante do grave problema da exclusão educacional, da extrema desigualdade social e da discriminação que permeiam as relações socioeconômicas no Brasil" (HAAS; LINHARES, 2012, p. 839).

Em resposta ao primeiro processo de seleção dos estudantes da UFFS, no início de 2010 se constituíram as primeiras turmas de ingressantes nos cursos de graduação da UFFS, cujas atividades acadêmicas começaram em 29 de. Conforme informações obtidas no "Relatório Evasão/Ocupação nos cursos de graduação da UFFS" ${ }^{8}$, para concorrer às 2.160 vagas dos cursos disponibilizados, inscreveram-se 11.212 candidatos, com uma média de disputa de 5,19 candidatos por vaga, sendo o curso de Engenharia

8 O referido Relatório, intitulado foi elaborado pelos membros do Grupo de Pesquisa em Educação Popular (GRUPEPU): Adriana Salete Loss; Adriana Regina Sanceverino Losso; Naira Estela Roesler Mohr; Sandra Hopner Pierozan; Thiago Ingrassia Pereira; Alexandre Luis Fassina. 
Ambiental e Energias Renováveis, ofertado no campus Chapecó, o mais procurado. Desses inscritos, aproximadamente $87 \%$ cursaram o ensino médio (integral ou parcialmente) em escola pública (UFFS, 2014b).

Em relação aos primeiros ingressantes na UFFS, em março de 2010, Rotta, Vitcel e Andrioli (2012, p. 61-62) destacam alguns números que caracterizam o seu perfil: “[...] 79\% não cursaram pré-vestibular; $87 \%$ são oriundos de famílias com renda de até cinco salários-mínimos; em sua maioria são trabalhadores assalariados; e $87 \%$ representam a primeira geração da família a chegar a um curso universitário". O percentual de estudantes da UFFS egressos da escola pública foi de 93,68\% e no ano de 2011 foi superior ao de 2010, pois chegou a 95,55\%.

Com base em Boletim Informativo da Universidade Federal da Fronteira Sul (UFFS, 2010c), a maioria dos estudantes que ingressaram na Instituição em 2010 era oriunda da região em que os cinco campi estão instalados, sendo em Chapecó, 67\%; em Erechim, 83\%; em Cerro Largo, 97\%; em Laranjeiras do Sul, 82\%; e, em Realeza, 71\%.

Em matéria publicada no site da UFFS, em fevereiro de 2010, encontram-se números que representam, por campus, a abrangência do critério de bonificação utilizado para compor a nota final dos candidatos aprovados, sendo amplamente contemplados os egressos da escola pública, sendo assim representados: "em Chapecó, dos 867 selecionados, $88 \%$ fizeram todo o ensino médio neste segmento do ensino; em Cerro Largo, foram 97\% dos 330 selecionados; em Laranjeiras do Sul, 94\% dos 216; em Erechim, 92\% dos 400 alunos e em Realeza 92\% de 270 estudantes" (UFFS, 2010d, p.1). Ao analisar o perfil dos estudantes que ingressaram em 2010, o então reitor pro tempore da UFFS, professor Dilvo Ristoff, assim se refere:

Estamos construindo uma universidade pública de acordo com a lógica da paridade entre as matrículas do ensino médio público e do ensino superior público, pois $89 \%$ do ensino médio brasileiro é público. [...] como esta paridade pode ser observada em todos os cursos da instituição, constata-se que a UFFS altera a lógica, historicamente 
tão criticada, que fazia com que na maioria dos cursos da IES públicas e gratuitas, especialmente nos cursos mais disputados, os alunos fossem oriundos das escolas privadas e pagas (UFFS, 2010d, p. 1).

Essa política de bonificação foi aplicada nos processos seletivos da UFFS, durante os três primeiros anos, tendo por base os editais específicos para cada ano, conforme demonstra o quadro $1^{9}$.

Quadro 1 - Editais de processos seletivos regulares, de 2010 a 2012

\begin{tabular}{|l|l|l|l|}
\hline Ano & Edital & Vagas & Política de acesso \\
\hline 2010 & $\begin{array}{l}\text { Edital } n^{\circ} \text { 003/UFFS/2009 (25 de } \\
\text { novembro de 2009). }\end{array}$ & 42 ofertas - 2.160 vagas & $\begin{array}{l}\text { Bonificação / “Fator } \\
\text { Escola Pública” }\end{array}$ \\
\hline 2011 & Edital $n^{\circ}$ 032/UFFS/2010 (18 de novembro de 2010). \\
\hline 2012 & Edital $n^{\circ}$ 162/UFFS/2011 (08 de novembro de 2011). \\
\hline
\end{tabular}
Fonte: UFFS (2009b; 2010e; 2011).

Durante os três primeiros anos, a UFFS não adotou nenhuma política com recorte étnico-racial, pois acreditou-se que estariam representados todos os segmentos da sociedade, excluídos historicamente do acesso à educação superior pública. Os dados dos ingressantes no ano de 2012 revelam que $85,0 \%$ são autodeclarados brancos. $\mathrm{O}$ fato de haver uma predominância de brancos na região da Mesorregião em que a UFFS está instalada pode ter sido um dos motivos pelos quais esse debate não esteve presente nos processos inaugurais da Universidade, conforme mencionado por Pereira (2014, p. 157). Para o autor, "a colonização da matriz europeia é muito significativa e sustenta boa parte de uma das atividades econômicas principais da região: a agricultura familiar".

A partir da aprovação da Lei no 12.711 , do Decreto $n^{\circ} 7.824$ e da Portaria Normativa MEC $n^{\circ} 18$, em agosto de 2012, a UFFS, para o ano letivo de 2013, aprimorou sua política de ingresso, em observância à aplicação de forma integral à "Lei das Cotas". No dia 03 de dezembro de 2012, foi aprovada na Câmara de Graduação, do Conselho Universitário, a Resolução no 006/2012 (UFFS, 2012a, p.1), que regulamentou o “modelo de implantação

9 Neste quadro não foram apresentados editais de retificação e/ou complementares. 
da reserva de vagas para a política de ingresso nos cursos de graduação da UFFS". Com essa política, a UFFS garantiu a implantação integral do sistema de reserva de vagas, conforme prevê a Lei no 12.711/2012.

Além da manutenção da característica do ENEM, a nova Política de Ingresso da UFFS definiu como critério que, para a reserva de vagas, em cada curso e turno, para os estudantes que cursaram todo o ensino médio em escola pública, seriam observados os resultados do último senso escolar da educação básica realizada pelo INEP/MEC, para cada Unidade da Federação do local de oferta de vagas da Universidade (UFFS, 2012a). Para a definição das vagas no edital do processo seletivo de 2013, os percentuais de escola pública encontrados para cada estado foram os seguintes: Paraná, 87\%; Santa Catarina, 86\%; e Rio Grande do Sul, 89\% (UFFS, 2012a).

Desses percentuais, é deduzido um percentual destinado para uma ação afirmativa específica da UFFS, assim definida:

Define-se, como ação afirmativa, a reserva de vagas, em cada curso e turno, para candidatos que tenham cursado o ensino médio parcialmente em escola pública (ao menos um ano com aprovação) ou em escola de direito privado sem fins lucrativos, cujo orçamento da instituição seja proveniente do poder público, em pelo menos 50\%. Parágrafo único: O percentual de vagas destinado a essa ação afirmativa basear-se-á no processo seletivo institucional, observando o percentual de candidatos inscritos com esse perfil (UFFS, 2012b, p. 2).

A título de ilustração, com base na nova Política de Ingresso da UFFS, o gráfico a seguir demonstra a reserva de vagas, a partir do critério de escola pública, conforme cada unidade da federação em que os campi estão instalados. 
Gráfico 3 - Percentual de vagas reservadas na UFFS por Estado

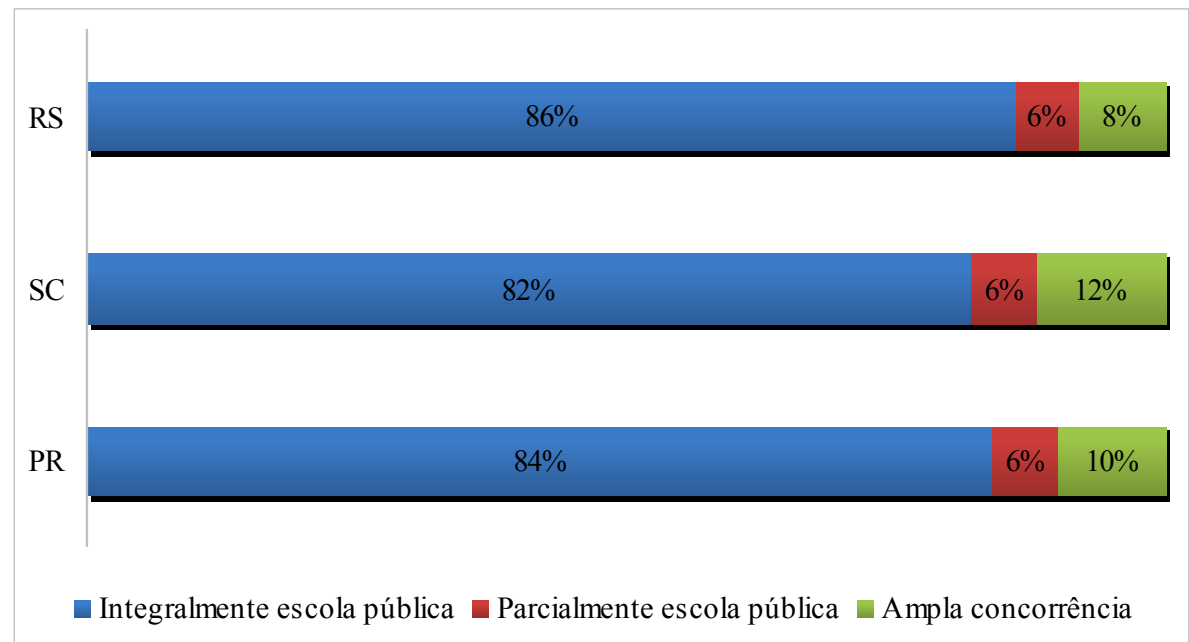

Fonte: Política de Ingresso de Graduação (UFFS, 2012a - elaborado pelos autores).

Ao criar uma ação afirmativa específica, pode-se afirmar que houve uma inovação na política de acesso da UFFS. Soma-se a isso o fato de se utilizar dos resultados do senso escolar para a reserva de vagas, pois assim são mantidos os percentuais já alcançados desde o início para os estudantes oriundos da escola pública.

Outro aspecto relevante da Política de Ingresso da UFFS, além da categoria administrativa da escola pública, foi a sua adequação à "Lei das Cotas", que exige, também, associada ao critério da escola pública, os aspectos étnico-raciais e de renda. Para atender tal exigência, a partir da dedução de um percentual destinado para essa ação afirmativa específica, os demais percentuais de vagas são reservados, considerando: 50\% para estudantes com renda bruta per capita familiar igual ou inferior a 1,5 salários-mínimos e 50\% para aqueles com renda superior a 1,5 salários-mínimos (UFFS, 2012b).

O gráfico 4 demonstra essa distribuição de reserva de vagas na UFFS para o ano de 2013, conforme a renda, para cada unidade da federação. 
Gráfico 4 - Percentual de reserva de vagas na UFFS, conforme a renda, por Estado

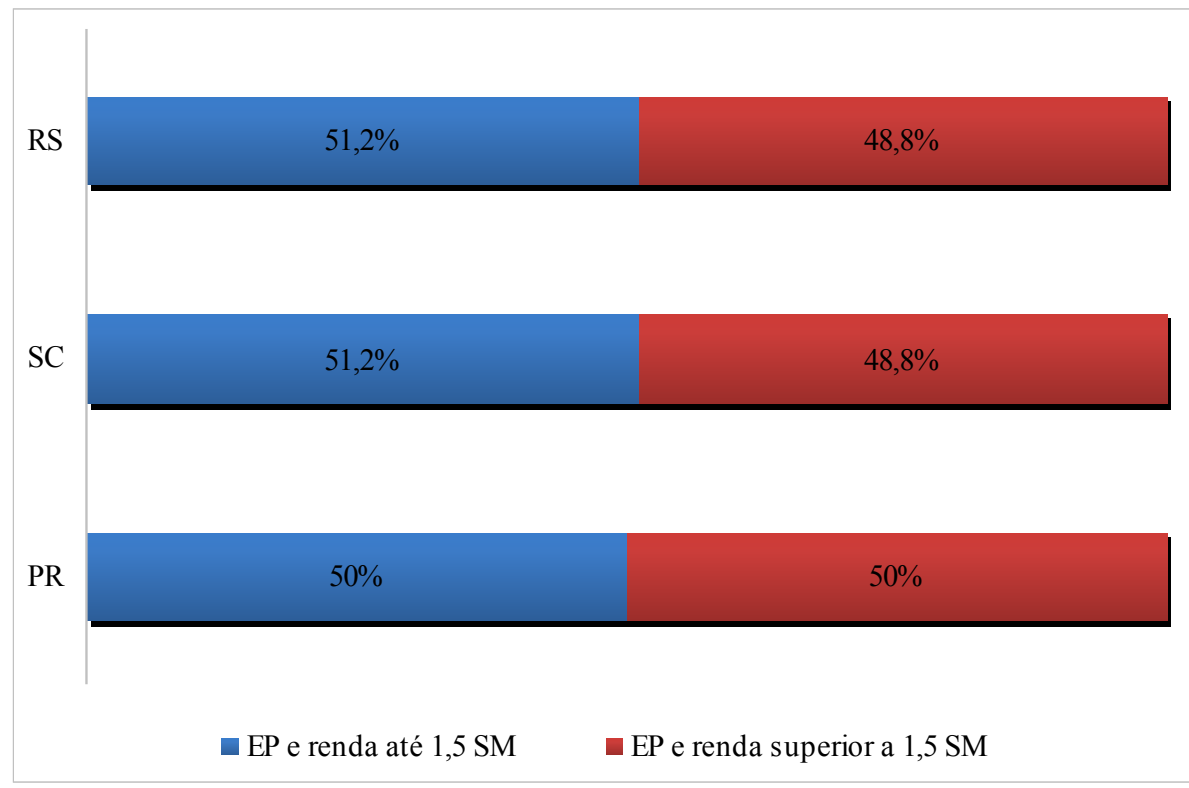

Fonte: Política de Ingresso de Graduação (UFSS, 2012a).

Nota: $\mathrm{EP}$ = escola pública; $\mathrm{SM}$ = salário-mínimo

A Política de Ingresso prevê ainda que dentro de cada um desses percentuais são reservadas vagas para estudantes autodeclarados pretos, pardos ou indígenas. Essa reserva é definida para cada curso e turno, "de acordo com os dados do censo demográfico mais recente do Instituto Brasileiro de Geografia e Estatística (IBGE) para cada Unidade da Federação do local de oferta de vagas da instituição" (UFFS, 2012b, p. 2).

O gráfico 5 demonstra essa distribuição na UFFS, para o ano de 2013, conforme o critério dos autodeclarados pretos, pardos e índios, para cada Unidade da Federação. 
Gráfico 5 - Percentual de vagas reservadas na UFFS, por Estado, conforme a autodeclaração de pretos, pardos e índios

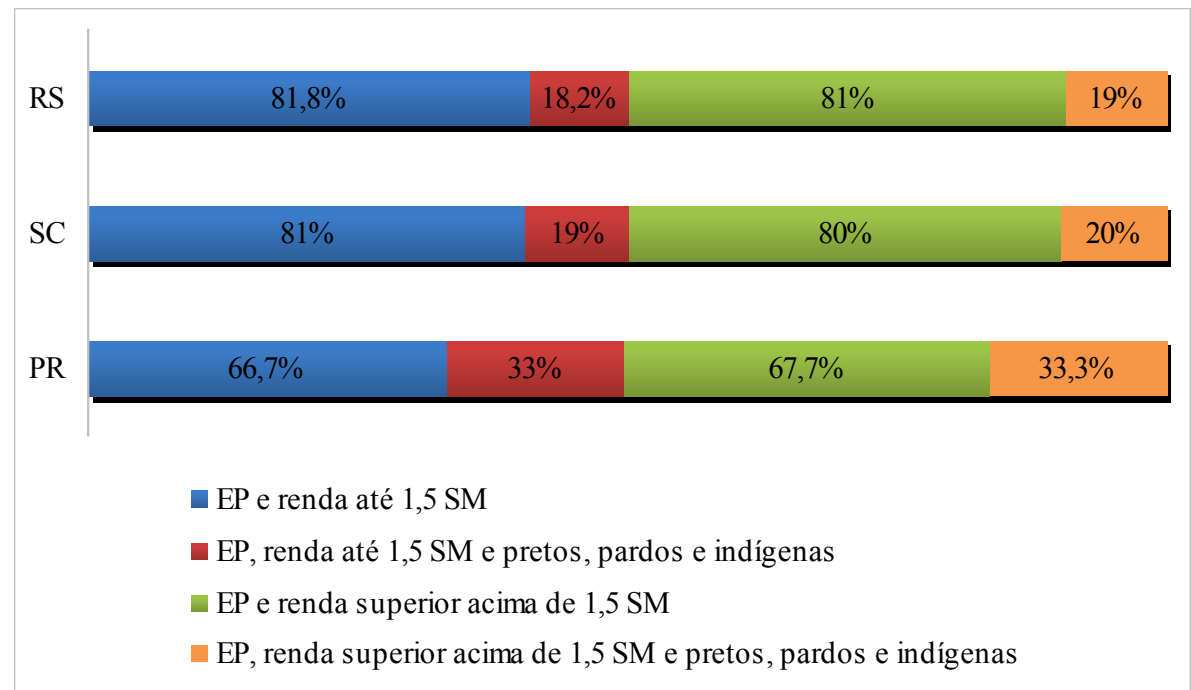

Fonte: Política de Ingresso de Graduação (UFSS, 2012a).

Nota: $\mathrm{EP}$ = escola pública; $\mathrm{SM}$ = salário-mínimo

Além disso, foram previstas duas vagas suplementares, uma para estudante preto e uma para estudante indígena, para os casos em que na última chamada, nenhum candidato preto e indígena tenha sido matriculado em cada curso. Será chamado o primeiro candidato nessa condição, desde que integre a lista de classificados. As demais vagas serão destinadas à ampla concorrência (UFFS, 2012b).

Dessa forma, em observância à Lei no $12.711 / 12$ e de acordo com a nova Política de Ingresso da UFFS, para o ano de 2013, no edital do processo seletivo, foram definidas cinco opções de grupos para a inscrição dos candidatos, devendo estes optar por uma das opções:

Grupo I - vagas reservadas a candidatos que cursaram integralmente o ensino médio em escola pública [...], que tenham renda familiar bruta igual ou inferior a 1,5 (um vírgula cinco) salário mínimo per capita e que se autodeclaram pretos, pardos ou indígenas. 
Grupo II - vagas reservadas a candidatos que cursaram integralmente o ensino médio em escola pública [...], que tenham renda familiar bruta igual ou inferior a 1,5 (um vírgula cinco) salário mínimo per capita.

Grupo III - vagas reservadas a candidatos que cursaram integralmente o ensino médio em escola pública [...], que tenham renda familiar bruta superior a 1,5 (um vírgula cinco) salário mínimo per capita e que se autodeclaram pretos, pardos ou indígenas.

Grupo IV - vagas reservadas a candidatos que cursaram integralmente o ensino médio em escola pública [...], que tenham renda familiar bruta superior a 1,5 (um vírgula cinco) salário mínimo per capita. Grupo V - vagas reservadas a candidatos que tenham cursado parcialmente o ensino médio em escola pública (pelo menos um ano com aprovação) ou em escolas de direito privado sem fins lucrativos, cujo orçamento da instituição seja proveniente do poder público, em pelo menos $50 \%$.

Grupo VI - vagas de ampla concorrência, destinadas a todos os candidatos, independente da procedência escolar, renda familiar e raça/cor (UFFS, 2012c, p. 2).

Para o ano de 2014, a UFFS aderiu ao Sistema de Seleção Unificada $(\mathrm{SISU})^{10}$, por meio da Resolução no 28/2013 - CONSUNI, aprovada em 17 de setembro de 2013 (UFFS, 2013a). Com base em informações do $\mathrm{MEC}^{11}$, o processo seletivo do SISU é realizado sempre no início de cada semestre e ocorre duas vezes ao ano, cujas inscrições são gratuitas e realizadas em única etapa pela internet. As vagas são ofertadas por todas as instituições federais de ensino superior do Brasil que aderem ao SISU e são destinadas aos candidatos participantes do ENEM. De acordo com a Portaria Normativa no 21/2012 (BRASIL, 2012d, p. 1), que dispõe sobre o SISU, no seu art. $2^{\circ}$ :

O SISU é o sistema por meio do qual são selecionados estudantes a vagas em cursos de graduação disponibilizadas pelas instituições públicas e gratuitas de ensino superior que dele participarem.

\footnotetext{
10 O SISU foi instituído pela Portaria Normativa MEC nº 2, de 26 de janeiro de 2010 e em 2012 passou a ser regido pelo disposto na Portaria Normativa no 21, de 05 de novembro de 2012.

11 Disponível em: <http://sisu.mec.gov.br/>. Acesso em: 09 out. 2014.
} 
$\$ 1^{\circ} \mathrm{O}$ processo de seleção dos estudantes para as vagas disponibilizadas por meio do SISU é autônomo em relação àqueles realizados no âmbito das instituições de ensino superior, e será efetuado exclusivamente com base nos resultados obtidos pelos estudantes no Exame Nacional do Ensino médio (ENEM).

Em dezembro de 2013, a UFFS assinou o primeiro Termo de Adesão ao SISU ${ }^{12}$, para a participação na primeira edição de 2014. O quadro 2 apresenta os editais de processos seletivos dos estudantes da UFFS, para o ingresso regular, conforme a nova Política de Ingresso, a partir da aprovação da Lei no $12.711 / 2012$.

Quadro 2 - Editais de processos seletivos regulares de 2013 a 2015/1

\begin{tabular}{|c|c|c|c|}
\hline Ano & Edital & Vagas & Política de Acesso \\
\hline 2013 & $\begin{array}{l}\text { Edital no 311/UFFS/2012 } \\
\text { (11 de dezembro de 2012). }\end{array}$ & $\begin{array}{l}37 \text { cursos / } 46 \text { ofer- } \\
\text { tas / } 2.025 \text { vagas }\end{array}$ & $\begin{array}{l}\text { Lei no } 12.711 / 2012 \\
\text { e ação afirmativa da } \\
\text { UFFS }\end{array}$ \\
\hline $2014 / 1$ & $\begin{array}{l}\text { Edital no 572/UFFS/2013 } \\
\text { (05 de dezembro de 2013). }\end{array}$ & $\begin{array}{l}36 \text { ofertas / } 1.590 \\
\text { vagas }\end{array}$ & \multirow{3}{*}{$\begin{array}{l}\text { SISU, Lei no } \\
12.711 / 2012 \text { e ação } \\
\text { afirmativa da UFFS }\end{array}$} \\
\hline $2014 / 2$ & $\begin{array}{l}\text { Edital no 282/UFFS/2014 } \\
(15 \text { de maio de 2014). }\end{array}$ & $\begin{array}{l}11 \text { ofertas / } 485 \\
\text { vagas }\end{array}$ & \\
\hline $2015 / 1$ & $\begin{array}{l}\text { Edital no } 812 / \text { UFFS/2014 } \\
\text { (19 de dezembro de 2014). }\end{array}$ & $\begin{array}{l}42 \text { ofertas / } 1.920 \\
\text { vagas }\end{array}$ & \\
\hline
\end{tabular}

Fonte: UFFS (2012c; 2013b, 2014c, 2014d).

A partir de 2014, com a entrada no SISU, ocorreram dois processos seletivos anuais de ingresso regular de estudantes. A política de reserva de vagas foi mantida, apenas com um ajuste no percentual de reserva de vagas para a ação afirmativa específica da UFFS, com base no critério de escola pública parcial. Esse percentual, que em 2013 era de 5\%, passou para 2\%, a partir dos processos seletivos de 2014. Também houve alguns ajustes ao processo do SISU quanto à disposição dos grupos, já mencionados, para a inscrição dos candidatos ${ }^{13}$ (UFFS, 2014c; 2014d).

12 Disponível em: <http://www.uffs.edu.br/ps2014/Termo_adesao_1528_Final.pdf>. Acesso em: 10 out. 2014.

$13 \mathrm{O}$ equivalente aos Grupos I, II, III, IV, V e VI passa a ter as seguintes nomenclaturas, L2, L1, L4, L3, A1 e AC (ampla concorrência), respectivamente. 
A partir desse breve histórico que caracteriza as políticas de acesso pela UFFS, implementadas nos seus primeiros anos de existência, é possível perceber aspectos positivos de inclusão realizados nesse período. Diante disso, considerou-se oportuno destacar que no início de novembro de 2014 a UFFS conquistou o "Prêmio Guia do Estudante - Destaques de 2014" na categoria Inclusão. Conforme notícia divulgada no site da instituição, "a premiação faz parte dos Prêmios Santander Universidades e tem como objetivo reconhecer as instituições de ensino superior que mais se destacaram no período de julho de 2013 a junho de 2014" (UFFS, 2014e, p. 1). Dentre as instituições de ensino superior do Brasil, foram encaminhadas à organização da premiação 2.466 inscrições, oriundas de 1.067 IES. A UFFS concorreu com o projeto "Política de Ingresso na Graduação", na categoria Inclusão, em que fez o destaque para a garantia de que $90 \%$ dos alunos da UFFS são egressos de escolas públicas. A notícia foi recebida com muito entusiasmo, pois revela o reconhecimento de uma política considerada inclusiva em âmbito nacional.

As políticas de acesso descritas até o momento integram a principal forma de acesso dos estudantes da UFFS, pela via exclusiva do ENEM e designada como Processo Seletivo Regular, conforme o Regulamento de Graduação da UFFS. A partir da criação dos cursos de graduação e autorização do seu funcionamento, as vagas são definidas pelo Conselho Universitário (CONSUNI) da instituição (UFFS, 2014a).

Além do processo seletivo regular, a partir das vagas não ocupadas são criadas modalidades de ingresso aos estudantes, conforme consta no Regulamento de Graduação, no $\$ 1^{\circ}$ do art. 25 (UFFS, 2014a, p. 16):

As vagas não ocupadas pelo processo seletivo regular, bem como aquelas resultantes da evasão de estudantes antes da conclusão do curso, quando existentes, são ofertadas em processos seletivos específicos para transferências interna e externa, retorno de aluno-abandono ou retorno de graduado. 
Além disso, está previsto no atual Regulamento a realização de processos seletivos diferenciados, com vistas a atender demandas específicas, com base no $\$ 2^{\circ}$, art. 25: "por definição da Câmara de Graduação, o acesso à universidade pelos indivíduos pertencentes a minorias sociais específicas pode ser feito através de processo seletivo diferenciado" (UFFS, 2014a, p. 16).

A partir da expansão de novos cursos e em atendimento às novas demandas de acesso que foram emergindo na UFFS, foram sendo implementados processos seletivos diferenciados para o ingresso aos cursos de graduação da UFFS.

\section{PROCESSOS SELETIVOS ESPECIAIS: EXPANSÃO DE CURSOS}

Em 2013 a UFFS iniciou um processo de expansão dos campi e dos cursos de graduação. Num primeiro momento foi criado o Campus Passo Fundo, que, no dia 24 de abril, por meio da Portaria no 323/MEC, teve autorizado o curso de Medicina, considerado o primeiro curso a ser autorizado e a entrar em funcionamento pela Política de Expansão das Escolas Médicas do Brasil. No mesmo ano, em 25 de julho, foi publicado o primeiro edital, no 309/UFFS/2013, para o processo seletivo do curso de Medicina, com a oferta de 40 vagas (UFFS, 2013c). No dia 19 de setembro foi publicado o Edital n ${ }^{\circ} 418$ /UFFS/2013, prevendo duas vagas suplementares para matrícula de mais duas candidatas, sendo uma autodeclarada preta e a outra indígena (UFFS, 2013d). Essa situação estava prevista no edital do processo seletivo, caso não tivesse sido matriculado nenhum estudante na condição de preto e indígena.

A partir de 2014, o acesso ao curso de Medicina passou a integrar o processo seletivo regular da Universidade. Conforme previsto no Edital $n^{\circ} 282 / U F F S / 2014$, para o curso de Medicina não foi disponibilizada vaga suplementar, conforme os demais cursos. Assim consta na redação: “[...] 
excetuando-se o curso de Medicina, para o qual a Universidade não possui autonomia para criar vaga suplementar, a UFFS garantirá vaga suplementar para candidatos autodeclarados pretos e indígenas" (UFFS, 2014c, p. 3).

Em julho de 2013, foi aprovada no CONSUNI a Resolução n 25/2013, que criou e autorizou o funcionamento de mais quatro cursos de graduação no âmbito da UFFS: História - Licenciatura ${ }^{14}$, Interdisciplinar em Educação do Campo: Ciências da Natureza - Licenciatura ${ }^{15}$, Interdisciplinar em Educação do Campo: Ciências Sociais e Humanas - Licenciatura e Matemática - Licenciatura. A oferta para todos os cursos é prevista na modalidade presencial e, com exceção do curso de Matemática, os demais são de oferta também em regime de alternância (UFFS, 2013e).

Para os três primeiros cursos, a Resolução previu a seleção dos estudantes por meio de processos seletivos específicos, regidos por editais próprios, publicados no ano de 2013. O curso de Matemática passou a ser ofertado junto ao processo seletivo regular da UFFS, uma vez ao ano, no primeiro semestre.

Além desses cursos, em fevereiro de 2014, foi aprovado pelo CONSUNI o curso de graduação em Agronomia - Bacharelado ${ }^{16}$, ofertado em regime de alternância, na modalidade presencial e em turno integral, com a oferta num assentamento de Reforma Agrária, no município de Pontão (UFFS, 2014f).

A distribuição de vagas para todos esses cursos está prevista conforme a Lei no ${ }^{\circ}$ 12.711/12 e em observância à Política de Ingresso na Graduação da UFFS. O quadro 3 apresenta um resumo com as principais informações dos respectivos cursos e os primeiros editais de processos seletivos.

\footnotetext{
14 Destinado à formação de jovens e adultos oriundos de assentamentos, no âmbito do Programa Nacional de Educação para Áreas da Reforma Agrária (PRONERA). Parceria firmada com o Instituto Técnico de Capacitação e Pesquisa da Reforma Agrária (ITERRA). O curso é ofertado em turma única.

$15 \mathrm{O}$ curso é destinado à formação de docentes para a atuação em escolas do campo. O ingresso é ofertado duas vezes por ano, totalizando 120 vagas anuais.

16 Destinado aos beneficiários do PRONERA. Parceria firmada com o Instituto Educar de Pontão, RS e o Instituto Nacional de Colonização e Reforma Agrária - INCRA/PRONERA. O curso é ofertado turma única.
} 
Quadro 3 - Editais de processos seletivos de novos cursos na UFFS (2013-2014)

\begin{tabular}{|l|l|l|l|l|}
\hline Ano & Edital & Campus & Curso & Vagas \\
\hline 2013 & $\begin{array}{l}\text { Edital no 382/UFFS/2013 } \\
(26 \text { de agosto de 2013) }\end{array}$ & $\begin{array}{l}\text { Campus Erechim, ofer- } \\
\text { tado no município de } \\
\text { Veranópolis, RS }\end{array}$ & História & 50 \\
\hline 2013 & $\begin{array}{l}\text { Edital no 458/UFFS/2013 } \\
(03 \text { de outubro de 2013) }\end{array}$ & Campus Erechim & $\begin{array}{l}\text { Interdisciplinar em } \\
\text { Educação do Campo: } \\
\text { Ciências da Natureza }\end{array}$ & 60 \\
\hline 2013 & $\begin{array}{l}\text { Edital no 502/ } \\
\text { UFFS/2013(29 de outu- }\end{array}$ & $\begin{array}{l}\text { Campus de Laranjeiras } \\
\text { do Sul } \\
(5 \text { de dezembro de 2013) }\end{array}$ & $\begin{array}{l}\text { Interdisciplinar em } \\
\text { Educação do Campo: } \\
\text { Ciências Humanas e } \\
\text { Sociais }\end{array}$ & 60 \\
\hline 2014 & $\begin{array}{l}\text { Edital no 098/UFFS/2014 } \\
(06 \text { de março de 2014 })\end{array}$ & $\begin{array}{l}\text { Campus Erechim, ofer- } \\
\text { tado no município de } \\
\text { Pontão, RS }\end{array}$ & Agronomia & 50 \\
\hline
\end{tabular}

Fonte: UFFS (2013f; 2013g; 2013h; 2013b; 2014g).

Cabe destacar, ainda, que, ao final do ano de 2013, em 12 de dezembro, a Universidade, por meio do Conselho Universitário, aprovou duas políticas de inclusão social voltadas para acesso e permanência de estudantes indígenas e para o acesso de estudantes haitianos na UFFS. E, em março de 2015, aprovou também uma política voltada para o acesso e permanência de estudantes e servidores com deficiência.

\section{PROGRAMA DE ACESSO À EDUCAÇÃO SUPERIOR PARA ESTUDANTES HAITIANOS (PROHAITI)}

A partir da chegada de imigrantes haitianos no Brasil e em número significativo na Região Sul, atraídos principalmente pela mão-de-obra nas grandes indústrias de alimentos, iniciou-se uma reivindicação para o acesso à educação superior na UFFS. Para o atendimento a esta demanda, em dezembro de 2013, foi aprovada pelo CONSUNI a Resolução no 32/2013, que "institui o Programa de Acesso à Educação Superior da UFFS para Estudantes Haitianos (PROHAITI) e dispõe sobre os procedimentos para operacionalização das atividades do programa” (UFFS, 2013i, p.1). 
O PROHAITI foi instituído por meio de uma parceria entre a UFFS e a Embaixada do Haiti no Brasil, tendo como objetivo "contribuir para integrar os imigrantes haitianos à sociedade local e nacional, por meio do acesso aos cursos de graduação da UFFS, e qualificar profissionais que ao retornar possam contribuir com o desenvolvimento do Haiti" (UFFS, 2013i, p. 1). O Programa consiste na oferta de vagas suplementares nos cursos de graduação da UFFS, para estudantes haitianos, que será avaliada anualmente, considerando estudos sobre a população de haitianos nos municípios de abrangência da UFFS e a ocupação das vagas que são ofertadas de forma regular no processo seletivo da UFFS. Para essa oferta, o acesso aos estudantes não ocorre pelo ENEM, mas por meio de um processo seletivo especial, regido por edital próprio.

A materialização desse programa teve início em fevereiro de 2014, com a publicação do primeiro processo seletivo especial, que ofertou vagas suplementares para os cursos de graduação da UFFS aos imigrantes haitianos, com ingresso no primeiro. E, assim, conforme demonstra mais detalhadamente o quadro 4 , foram sendo publicados novos editais, a partir do semestre seguinte.

Quadro 4 - Editais de processos seletivos especiais (PROHAITI)

\begin{tabular}{|l|l|l|l|}
\hline Ano & Edital & Campus / Curso & Vagas \\
\hline 2014/1 & $\begin{array}{l}\text { Edital no 38/UFFS/2014 (07 de } \\
\text { fevereiro de 2014) }\end{array}$ & $\begin{array}{l}\text { Todos os campi }{ }^{17} \text {, exceto o Campus } \\
\text { Passo Fundo, 35 cursos }\end{array}$ & 135 \\
\hline 2014/2 & $\begin{array}{l}\text { Edital no 359/UFFS/2014 (20 de } \\
\text { junho de 2014) }\end{array}$ & Campus Chapecó, 8 cursos & 16 \\
\hline 2015/1 & $\begin{array}{l}\text { Edital no 052/UFFS/2015 (09 de } \\
\text { fevereiro de 2015) }\end{array}$ & Campus Chapecó, 12 cursos & 24 \\
\hline
\end{tabular}

Fonte: UFFS (2014h; 2014i; 2015a).

A partir do resultado do primeiro processo seletivo especial, foram matriculados 27 haitianos, apenas no Campus Chapecó. Nos demais campi 
91

não houve nenhuma matrícula ${ }^{18}$. Os demais editais passaram a abrir vagas de graduação somente para o Campus Chapecó.

No âmbito da pós-graduação, no dia 07 de março de 2014, foi publicado o edital $n^{\circ}$ 100/UFFS/2014, que instituiu um processo seletivo especial para candidatos haitianos para o Programa de Mestrado em Agroecologia e Desenvolvimento Sustentável, ofertado no Campus Laranjeiras do Sul, com duas (2) vagas para o ingresso no primeiro semestre de 2014 (UFFS, 2014j).

\section{PROGRAMA DE ACESSO E PERMANÊNCIA DOS POVOS INDÍGENAS (PIN)}

Com relação à inclusão de estudantes indígenas na UFFS, esse debate teve início ainda no ano de 2012. E, em 19 de abril de 2012, foi formada uma Comissão, designada pela Portaria no 385/GR/UFFS/2012 (UFSS, 2012d, p. 1), para a "elaboração da política indígena da UFFS nas áreas de ensino, pesquisa e extensão". A Comissão finalizou seus trabalhos e submeteu ao CONSUNI uma minuta que foi aprovada em dezembro de 2013, em forma de Resolução, no 33/2013, que “institui o Programa de Acesso e Permanência dos Povos Indígenas (PIN) da Universidade Federal da Fronteira Sul" (UFFS, 2013j, p. 1).

O PIN é destinado aos estudantes que pertençam aos povos indígenas e constitui-se em um instrumento na Universidade para a "promoção dos valores democráticos, de respeito à diferença e à diversidade socioeconômica e étnico-racial, mediante a adoção de uma política de ampliação do acesso aos seus cursos de graduação e pós-graduação e de estímulo à cultura, ensino, pesquisa, extensão e permanência” (UFFS, 2013j, p. 2).

No que tange às formas de ingresso aos cursos de graduação, a Resolução definiu as seguintes: 
92

I - de acordo com o definido através da Resolução nº 6/201 - CONSUNI/CGRAD (Política de Ingresso da UFFS), via ENEM/SISU;

II - mediante Processo Seletivo Exclusivo Indígena, com 2 (duas) vagas suplementares por curso, excetuando-se aqueles para os quais a Universidade não tem autonomia para ofertar vagas suplementares; III - mediante Processo Seletivo Especial, para atender demandas específicas, por meio de aprovação de projeto pelo CONSUNI (UFFS, 2013j, p. 3).

No âmbito da pós-graduação, a Resolução, no seu art. $8^{\circ}$, prevê: "ficam reservadas 2 (duas) vagas em cada um dos cursos de pós-graduação lato sensu e stricto sensu ofertados pela UFFS para candidatos autodeclarados indígenas, classificados no processo seletivo" (UFFS, 2013i, p. 3). Além das formas de acesso, a Resolução também dispõe sobre várias ações relacionadas à permanência desses estudantes na Universidade. Para o acompanhamento e a garantia do bom andamento do Programa foi prevista a formação de uma comissão geral, formada por membros de todos os campi e uma comissão local, formada em cada campus. As referidas comissões (geral e local) foram formalizadas por meio de portarias institucionais, durante o primeiro semestre de 2014.

Em cumprimento a esta Resolução, dois programas de pós-graduação, a partir de 2014, nos seus editais de seleção, passaram a prever a reserva de duas vagas para candidatos autodeclarados indígenas: o Programa de Pós-Graduação em Educação, por meio do edital no 039/UFFS/2014 e o Programa de Pós-Graduação em Estudos Linguísticos, pelo edital n469/ UFFS/2014 (UFFS, 2014k; 2014l).

Em 24 de outubro de 2014, foi lançado na UFFS o primeiro edital (nº 678/UFFS/2014) do Programa de Acesso e Permanência dos Povos Indígenas (PIN), que prevê a abertura de um processo seletivo especial, destinado aos estudantes autodeclarados indígenas, para provimento de vagas suplementares aos cursos de graduação da Universidade. Nesse edital foram ofertadas 2 vagas suplementares para cada curso, totalizando 82 
vagas, distribuídas entre todos os campi, exceto o Campus Passo Fundo, da seguinte forma: Chapecó (28); Cerro Largo (14); Erechim (16); Laranjeiras do Sul (12) e Realeza (12) (UFFS, 2014m).

De acordo com publicação no site da UFFS, em abril de 2015, o número de estudantes indígenas da Instituição é de 151, e, destes, 148 são da graduação. No Brasil, conforme aponta a mesma matéria, com base em dados do Ministério da Educação, existem 13.687 estudantes indígenas e 932 na Região Sul (UFFS, 2015b).

\section{POLÍTICA DE ACESSO E PERMANÊNCIA DA PESSOA COM DEFICIÊNCIA, TRANSTORNOS GLOBAIS DO DESENVOLVIMENTO E ALTAS HABILIDADES/ SUPERDOTAÇÃO}

A presença de estudantes com deficiência na UFFS sempre demandou o desenvolvimento de ações específicas por parte de alguns setores da Universidade. Essas ações estão asseguradas em legislação para que os estudantes possam usufruir do direito à educação com qualidade.

A partir da formação de grupos de trabalho para a organização de ações em prol da questão da deficiência na UFFS, em novembro de 2012, foi aprovada pelo Conselho Universitário uma Resolução ${ }^{19}$ que instituiu o Núcleo de Acessibilidade da UFFS e setores de acessibilidade, em cada campus da UFFS.

Após um período de trabalho do respectivo Núcleo e Setores de acessibilidade, foi aprovada em março de 2015, pela Câmara de Graduação do Conselho Universitário, a Resolução n 4/2015 - CONSUNI/CGRAD que institui a "Política de Acesso e Permanência da Pessoa com Deficiência, Transtornos Globais do Desenvolvimento e Altas Habilidades/ Superdotação na UFFS” (UFFS, 2015c, p. 1). 
Conforme a referida Política, os ingressos nos cursos de graduação da UFFS são regidos pela Política de Ingresso já vigente na instituição. Para a graduação não existe previsão de vagas específicas para as pessoas com deficiência. No que tange aos cursos de pós-graduação lato sensu e stricto sensu, foi previsto o seguinte:

I - fica reservada 1 (uma) vaga em cada um dos cursos de pós-graduação lato sensu e stricto sensu ofertados pela UFFS para candidatos com deficiência, classificados no processo seletivo;

II - nos casos em que houver mais candidatos aprovados que o número de vagas previsto, ocupará a vaga aquele que obtiver maior pontuação, de acordo com os critérios definidos pelo edital específico do curso de pós-graduação;

III - não havendo candidatos com deficiência para ocuparem a vaga, esta será preenchida por outro candidato, obedecendo a ordem de classificação (UFFS, 2015c, p. 4).

No que tange ao concurso de servidores para a UFFS, a Política prevê a reserva de um percentual de $5 \%$ do total das vagas em cada cargo, com base no que dispõe a Lei no 8.112 , de 11 de dezembro de 1990, e o Decreto $\mathrm{n}^{\circ} 3.298$, de 20 de dezembro de 1999, e suas alterações. (UFFS, 2015c).

Além de ações específicas destinadas ao acesso de pessoas com deficiência na UFFS, a referida Política também prevê ações para a permanência na Universidade. São ações que vão desde o apoio acadêmico até a garantia de serviços, ambientes e recursos que facilitam a aprendizagem dos estudantes e o trabalho desenvolvido pelos servidores, sejam docentes ou técnicos administrativos.

Devido à característica de abrangência de estudantes e servidores nesta Política, está previsto o seu acompanhamento por vários setores da UFFS: os Setores e a Divisão de Acessibilidade, os Setores de Assuntos Estudantis e o Departamento de Qualidade de Vida no Trabalho (UFFS, 2015c). 